\title{
DC-DC High Voltage Multiplier for Small Satellite GPR
}

\author{
Ravi K Tanti', Saurabh Warathe ${ }^{2}$ and Sharmik Admane ${ }^{3}$ \\ ${ }^{1,2,3}$ Department of Electronics Engineering, Shri Ramdeobaba College of \\ Engineering and Management Nagpur, Maharashtra, India
}

\section{ABSTRACT}

The purpose of research in this paper is to satisfy the power constraints of small satellite missions and rover equipped with GPR's. As a large number of rovers are solar powered and battery-operated generating output voltages between $28 \mathrm{~V}$ to $32 \mathrm{~V}$. The GPR works on high voltage Radar pulses hence we require a circuit converting the low voltage of battery to high voltage and for the same, we have proposed a DC to DC converter that converts few Volt to few Kilo Volt which is required by various applications such as RF antennas for transmission of data and making the GPR's suitable for small space missions. In this research, the concept of voltage multiplier is used and a modified Dickson charge pump is designed to generate $400 \mathrm{~V}$ DC from $30 \mathrm{~V}$ DC and is ideal for battery operated applications. The main advantage is that the overall size of the booster circuit is very small and hence adequately fits the weight constraints which are favorable for small space missions and can fit into small compact rovers and satellites.

KEY WORDS: CHARGE PUMP (CP), GROUND PENETRATION RADAR (GPR), HIGH-VOLTAGE-GAIN DC-DC POWER ELECTRONIC CONVERTER, MODIFIED DICKSON CHARGE PUMP, VOLTAGE MULTIPLIER (VM).

\section{INTRODUCTION}

The electromagnetic (EM) waves are the key components innumerous applications such as communication, medical instrument, and scientific exploration. Ground Penetration Radar is one of the applications which operates on the principle of propagation of EM waves. In the real world, GPR based equipment's used by civil engineers, archeologists, ore miners and bomb/mine detectors and several more. To conduct scientific experiments for extraterrestrial missions along with rovers, GPR was used to investigate interior geological structure. In 1973, Apollo Lunar Sounder Experiment (ALSE) carried under the US Apollo mission program with the help of multiband GPR. A GPR uses a non-destructive method

\section{ARTICLE INFORMATION}

*Corresponding Author: ravitanti5@gmail.com

Received 17th Oct 2020 Accepted after revision 24th Dec 2020

Print ISSN: 0974-6455 Online ISSN: 2321-4007 CODEN: BBRCBA

Thomson Reuters ISI Web of Science Clarivate Analytics USA and Crossref Indexed Journal

\section{Clarivate
Analytics}

NAAS Journal Score 2020 (4.31)

A Society of Science and Nature Publication,

Bhopal India 2020. All rights reserved.

Online Contents Available at: http//www.bbrc.in/

Doi: http://dx.doi.org/10.21786/bbrc/13.14/107 in which a nano second pulse of very high magnitude is transmitted by a narrow band antenna and which encounters with the surface.

When the electromagnetic pulse strikes the surface, a fraction of pulse gets absorbed, remaining gets reflected as shown in Fig 1 . The reflected portion is then collected by the broadband receiving antenna. On analyzing the reflected waves, the results are usually presented similar to seismic data, where the hyperbolas are observed. By processing the data, we can determine the depth and the dielectric constant of material. The reflection component is the factor of power which is reflected after scatting and absorption which is given by equation (1) where the reflecting component depends on material dielectrics constant $\mathrm{K} 1$ and $\mathrm{K} 2$.

$$
R=\frac{\sqrt{K 1}-\sqrt{k 2}}{\sqrt{K 1}+\sqrt{K 2}}
$$

Where $\mathrm{R}$ is the reflected power coefficient and $\mathrm{K} 1$ and $\mathrm{K} 2$ are the dielectric constants of the material.

The reflected pulse after filtering is sampled, which will give us the reflection time and by which we can determine

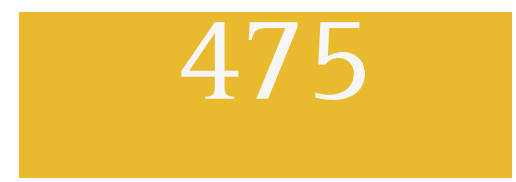


the dielectric constant of material using equation (2). Whereas $(\mathrm{nS})$ is reflection time, distance is in (feet) and $(\sigma)$ is dielectric constant.

$$
\frac{n S}{f t}=2 * \sqrt{\sigma}
$$

Figure 1: Transmitted and reflected component of Incident wave

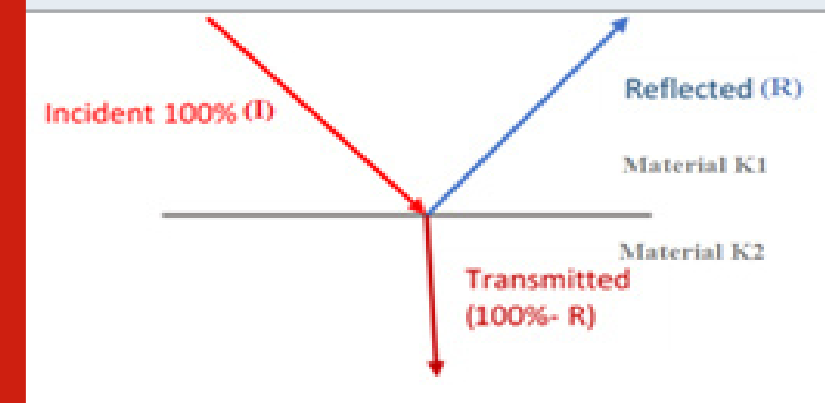

Figure 2: Block diagram of the GPR system and its main components.

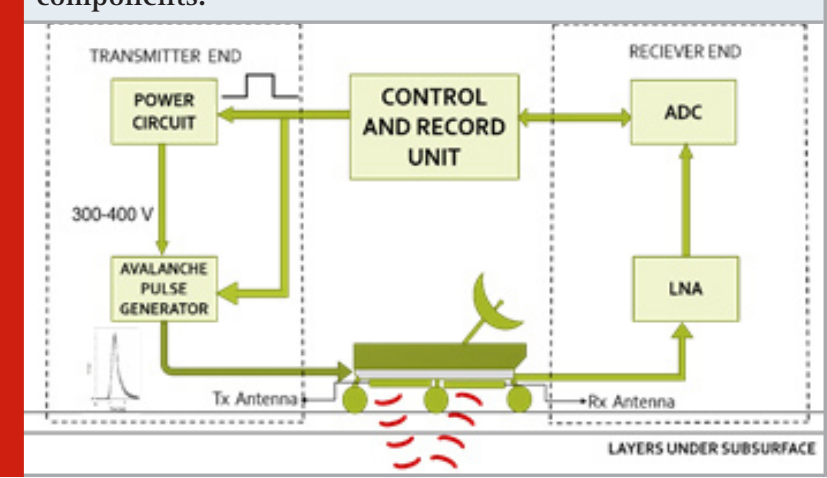

To generate a high voltage (HV) nanosecond pulse of $350 \mathrm{~V}$ to $400 \mathrm{~V}$ in the transmitter for GPR, Avalanched Pulse Generator is used as shown in Fig 2, which consists of HV and low current power circuit. As this GPR would be installed in small rovers or nanosatellites, there is a stringent constraint and hence there is a need for efficient and lightweight voltage booster circuit. According to a literature work, to boost the voltage Dickson CP can be used, as regardless of many different topologies the conventional boost converter has advantages like few numbers of components which translate into system cost reduction, as the rover is battery operated and has limited power, battery will drain at a faster rate therefore traditional Dickson CP cannot be used, therefore a modified circuit is proposed in section II of this paper.

With the help of rover equipped with GPR we can easily detect permafrost present beneath the surface without actually digging. In 2013, YUTU rover was deployed by CNSA wherein on the lunar surface which operated on frequencies $40-80 \mathrm{MHz}$ and $250-750 \mathrm{MHz}$. The Marx bank in the rover produced a pulse of peak amplitude 398.2 $\mathrm{V}$ at a $100 \Omega$ load. The planetary GPR discussed above in this paper uses a simple impulse generator with an operating frequency of $500 \mathrm{MHz}$, since lower the frequency, more the depth and lesser the resolution, for which the pulse width is 2 ns and has a peak voltage of 350-400V. This narrow pulse of energy is fed to the transmitting antenna having a center frequency of $500 \mathrm{MHz}$, which acts as a filter and produces a wave that is broadcasted. Then the reflected waves are collected by the receiving antenna as a function of time.

Research work proposed in has achieved a similar objective to generate $400 \mathrm{~V}$ from an input of $30 \mathrm{~V}$. But when considering celestial mission's, size plays a vital role in designing any system. As this design uses heavy and bulky components like transformer and switches which contributed to the main loss of power in circuit. Therefore, a similar design is proposed in this paper which removes the necessity of transformer and can work efficiently with only two switches as shown in Fig 3.

Figure 3: Block diagram for power supply in GPR



Figure 4: Dickson charge pump.

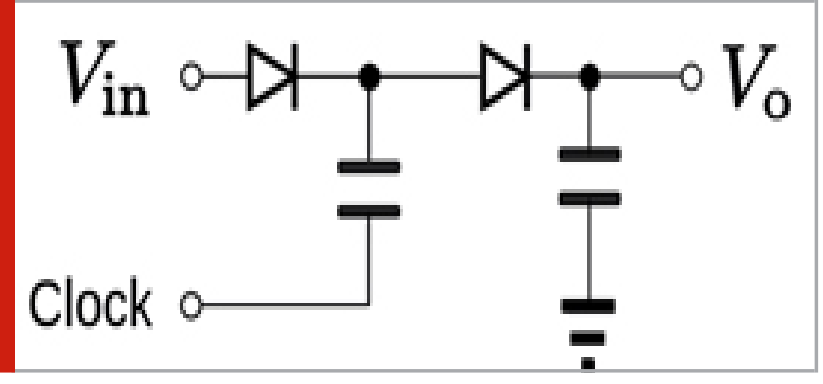

Dickson CP can be used to generate a voltage from few volts to few kilovolts for electronic appliances, it offers better efficiency, higher reliability at an improved power quality and low cost compared to AC distribution systems. This circuit can be used in applications requiring variable high voltage having weight constraints such as small payload satellite, data transmitting antenna, power delivery to multiple processors, and GPR. The use of classic boost and buck-boost converters require high duty ratios, which results in high component stress and lower efficiency. Isolated topologies like fly-back, forward, half-bridge, full-bridge, and push-pull converters have discontinuous input currents and hence, would require large input capacitors. 
2. Dickson Charge Pump: Distribution systems working at $400 \mathrm{~V}$ DC have been gaining admiration as they offer enhanced efficiency and greater reliability at an enriched power quality, and low cost compared to AC distribution systems. The Dickson CP or Dickson multiplier consists of a cascade of diode/capacitor cells with the bottom plate of each alternate capacitor driven by a train of the clock pulse. However, a voltage doubler, shown in Fig 4 , requires only one stage of multiplication, only one clock signal is required.

The Dickson CP is not preferred for space missions because of its exiguous size constraints. In a previous research work the value of VM capacitors and output capacitor was $60 \mathrm{nF}$ and $22 \mathrm{nF}$ respectively, and hence the overall size of the circuit increased. The Dickson $\mathrm{CP}$ requires two high-frequency clocks for driving the circuit which are in different phases which leads to difficulties in matching the frequencies. Therefore, a rectified and modified version is proposed such that it fits the weight limitations as well as the problem of frequency matching and the requirement of two clock cycles were also resolved.

\section{Proposed Dickson Charge Pump For Battery Operated} Appliances: The proposed Dickson CP circuit shown in Fig. 5, offers high DC voltage while conserving battery power. The input voltage is a modified square wave (MSW) having a peak of voltage equal to VIN. The voltages of the capacitors in the Dickson CP double at each stage as one transfers from the input-side capacitor to the load-side capacitor. Voltage increases with the stages which give the flexibility to run different equipment having different voltage requirements with a single power source. For an output voltage of VOUT= $400 \mathrm{~V}$. In Fig 5, there is a controlling element present between VIN and the CP. For RADAR application and GPR's the signals need not be sent continuously hence no continuous power supply is required. As the pulse generator requires high voltage for a very small instance of time so, it draws power from source/battery for the time required to reach $400 \mathrm{~V}$ and for the time required to transmit data. As soon as the data is transmitted, the supply is disconnected from the circuit and hence power is not wasted.

Figure 5: Proposed Dickson charge

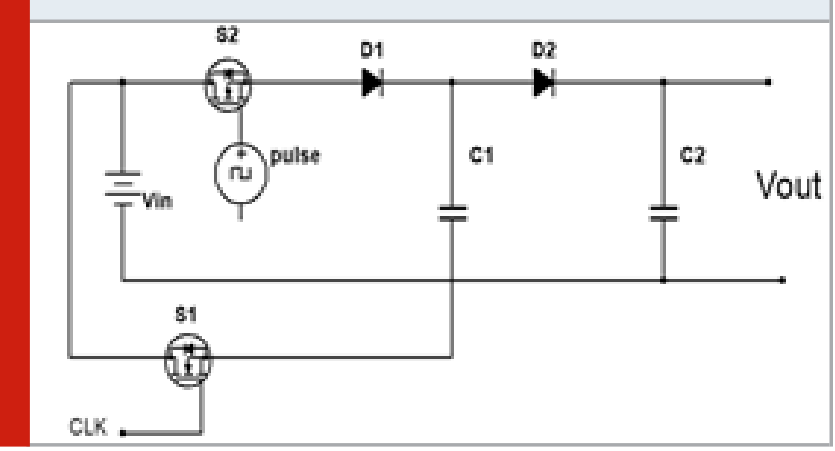

Figure 6: Output curve for the given input.



4. Topology And Operation: The improvised converter provides a high voltage gain using the modified circuit. It is composed of cascaded diode and capacitors, where each alternate capacitor is fed by a continuous square wave through switching MOSFET S1 refer Fig 5. Whereas switching MOSFET S2 is fed by a square pulse. Fig 6. shows the simulated result of the output waveforms for the proposed circuit. As soon as the switch S2 is turned on and square wave is applied to S1, the voltage does not reach $400 \mathrm{~V}$ instantly, it takes some initial time to attain a maximum of $400 \mathrm{~V}$ this is the setup time for the proposed circuit.

\section{Theoretical Analysis}

VOUT $=N\left(V_{P P}-V_{D}\right)+V_{D C}$

From equation (3) we can determine the output voltage for the given circuit. The output voltage from the first stage where $\mathrm{N}=1$ was found to be $45 \mathrm{~V}$. Similarly, the output voltage for 26th stage i.e. $\mathrm{N}=26$ was found to be $420 \mathrm{~V}$.

Figure 7: Circuit diagram of 26 stage

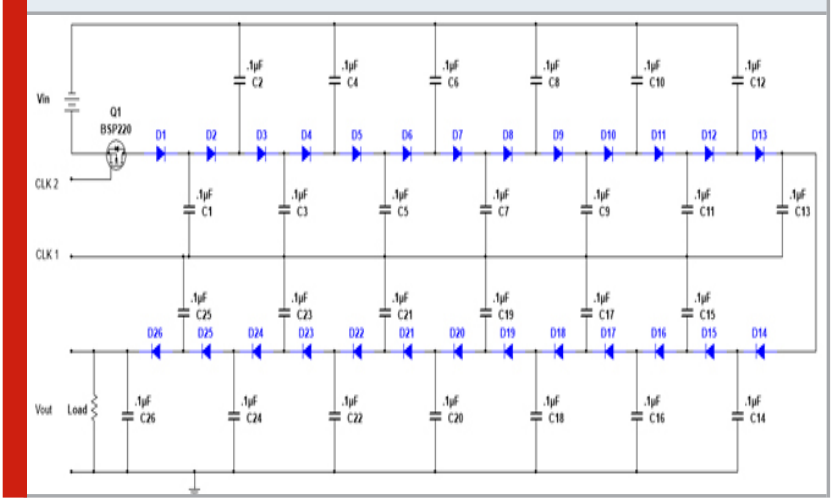

The circuit consists of 26 capacitor (C1 - C26) and 26 diodes (D1 - D26) connected in a cascaded form as shown in Fig. 7. Each stage is charged with $30 \mathrm{~V}$ square wave, where diode acts as a switch. In positive cycle the diode is forward bias hence it charges the capacitor and then passes 2VIN to another stage, where the pulse of another 
4. Topology And Operation: The improvised converter provides a high voltage gain using the modified circuit. It is composed of cascaded diode and capacitors, where each alternate capacitor is fed by a continuous square wave through switching MOSFET S1 refer Fig 5. Whereas switching MOSFET S2 is fed by a square pulse. Fig 6. shows the simulated result of the output waveforms for the proposed circuit. As soon as the switch S2 is turned on and square wave is applied to S1, the voltage does not reach $400 \mathrm{~V}$ instantly, it takes some initial time to attain a maximum of $400 \mathrm{~V}$ this is the setup time for the proposed circuit.

Theoretical Analysis

VOUT $=N\left(V_{P P}-V_{D}\right)+V_{D C}$

From equation (3) we can determine the output voltage for the given circuit. The output voltage from the first stage where $\mathrm{N}=1$ was found to be $45 \mathrm{~V}$. Similarly, the output voltage for 26 th stage i.e. $\mathrm{N}=26$ was found to be $420 \mathrm{~V}$.

The circuit consists of 26 capacitor (C1 - C26) and 26 diodes (D1 - D26) connected in a cascaded form as shown in Fig. 7. Each stage is charged with $30 \mathrm{~V}$ square wave, where diode acts as a switch. In positive cycle the diode is forward bias hence it charges the capacitor and then passes 2VIN to another stage, where the pulse of another stage is shifted by 2VIN with reference to previous voltage level and then it is given as input to another stage and so on till 26 stages. The interconnections are realized through diodes, through switches like S1. The value of the open-circuit output voltage VOUTMAX depends on the number of capacitors $\mathrm{N}$.

Figure 8: Duty Cycle analysis for 26 stages.

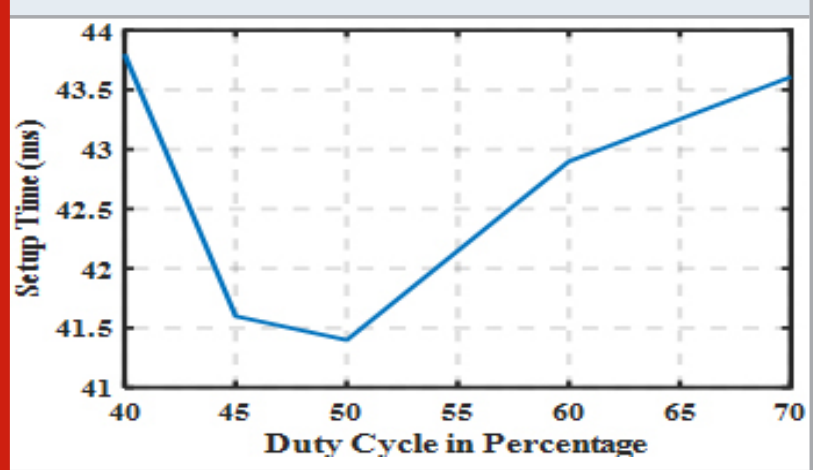

5. Experimental Results: The given designs were tested to obtain parameters like operating frequency, duty cycle, voltage factor and rise time using diverse simulation software and hardware implementation.

a. Duty Cycle Analysis: The input in S1 determines the setup time for the circuit. Frequency and duty cycle are the main parameters which regulate the setup time. The frequency was kept constant to $100 \mathrm{KHz}$ and the duty cycle was varied and the setup time reached to $400 \mathrm{~V}$. To conclude From Fig 8. it can be observed that as the duty cycle increases, the setup time decreases and then increases gradually with the increase in the duty cycle. Hence, the minimum setup time is $41.4 \mathrm{~ms}$ which is achieved at 50\% duty cycle.

Table 1: Frequency Analysis

\begin{tabular}{|c|c|c|}
\hline Sr. No & Frequency (in Hz) & Setup time \\
\hline 1 & 100 & $8.31 \mathrm{~s}$ \\
\hline 2 & 500 & $1.71 \mathrm{~s}$ \\
\hline 3 & $1 \mathrm{~K}$ & $876.4 \mathrm{~ms}$ \\
\hline 4 & $10 \mathrm{~K}$ & $101.12 \mathrm{~ms}$ \\
\hline 5 & $50 \mathrm{~K}$ & $43.89 \mathrm{~ms}$ \\
\hline 6 & $100 \mathrm{~K}$ & $41.4 \mathrm{~ms}$ \\
\hline 7 & $300 \mathrm{~K}$ & $40.8 \mathrm{~ms}$ \\
\hline
\end{tabular}

b. Frequency Analysis: On a similar basis, an experiment is performed by taking multiple input frequencies at $\mathrm{S} 1$ with a fixed duty cycle i.e. $50 \%$ and setup time is noted until the output reaches $400 \mathrm{~V}$ refer to Table 1 . From Table 1 , it can be concluded that as the frequency increases, the setup time decreases and after a particular limit it becomes constant. Therefore, there will be no significant change in setup time after a threshold frequency.

c. Voltage stress Across Capacitor and Diodes: In Table 2, voltage across the capacitor is measured from C1 to C26. Voltage across the capacitor increases as the number of stages increases hence, the capacitor used in the circuit should be rated above VOUT. Whereas the voltage across the diode is constant through the circuit i.e. $15 \mathrm{~V}$.

Table 2. Theoretical Analysis

\begin{tabular}{|l|c|c|}
\hline Sr. No & Capacitor & Voltage (V) \\
\hline 1 & C2 & 60 \\
\hline 2 & C4 & 90 \\
\hline 3 & C6 & 120 \\
\hline 4 & C8 & 150 \\
\hline 5 & C10 & 180 \\
\hline 6 & C12 & 210 \\
\hline 7 & C14 & 240 \\
\hline 8 & C16 & 270 \\
\hline 9 & C18 & 300 \\
\hline 10 & C20 & 330 \\
\hline 11 & C22 & 360 \\
\hline 12 & C24 & 390 \\
\hline 13 & C26 & 420 \\
\hline
\end{tabular}

To study the voltage stress across each capacitor and diode, an experiment was conducted in which the voltage across each capacitor was calculated, it was found that as the number of stages increases, the voltage stress on each capacitor increases but the voltage across diode remains almost constant irrespective of the number of stages. 
From table. 3 the voltage across diode was found to be $\sim 15 \mathrm{~V}$. In order to verify the analytical result, simulations were performed, the difference between the analytical result (table. 2.) and the simulation result (table. 3.) is less than $10 \%$. Hence, the analytical expression is still effective for the $\mathrm{CP}$.

d. Rise time fall time Analysis: The time required for a pulse to rise from $10 \%$ to $90 \%$ of its steady state value is its rise time. In this analysis, the rise time of the circuit is tested for a different number of stages and then for three different input voltages.

Table 4. Rise Time For Different Input Voltages and No. of Stages.

\begin{tabular}{|l|l|c|c|c|c|}
\hline \multicolumn{2}{|c|}{ For 10 v $/ \mathrm{P}$} & \multicolumn{2}{c|}{ For 20 v I/P } & \multicolumn{2}{c|}{ For 30v I/P } \\
\hline $\begin{array}{l}\text { No. } \\
\text { of } \\
\text { Stages }\end{array}$ & $\begin{array}{c}\text { Rise } \\
\text { Time } \\
(\mathrm{mS})\end{array}$ & $\begin{array}{c}\text { No. } \\
\text { of } \\
\text { Stages }\end{array}$ & $\begin{array}{c}\text { Rise } \\
\text { Time } \\
(\mathrm{mS})\end{array}$ & $\begin{array}{c}\text { No. } \\
\text { of } \\
\text { Stages }\end{array}$ & $\begin{array}{c}\text { Rise } \\
\text { Time } \\
(\mathrm{mS})\end{array}$ \\
\hline 6 & 1.73 & 6 & 1.498 & 6 & 1.373 \\
\hline 12 & 6.492 & 12 & 5.618 & 12 & 4.99 \\
\hline 18 & 13.75 & 18 & 11.99 & 18 & 11.15 \\
\hline 22 & 22.04 & 22 & 17.44 & 22 & 16.47 \\
\hline 26 & 27.34 & 26 & 24.48 & 26 & 22.97 \\
\hline
\end{tabular}

Figure 9: Dependence of rising time on No. of stages and I/P voltages.

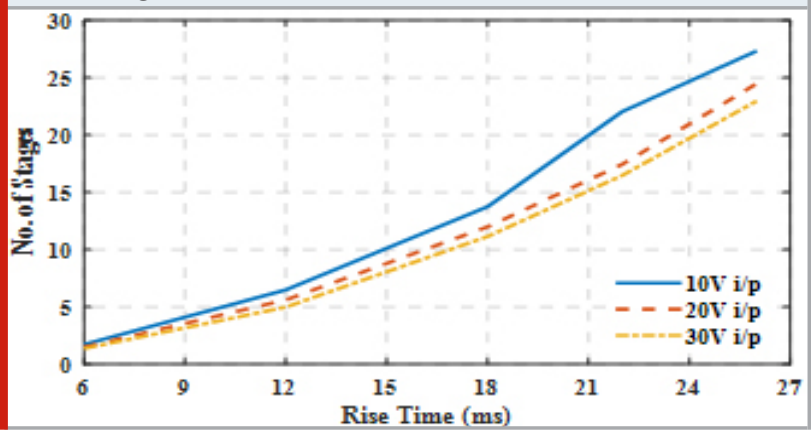

Fig. 9 shows the dependency of rising time on the optimum number of stages and different input voltages. The rise time proportionally increases with the number of stages in case of a large number of stages. On the other hand, from table 4 , we observe that the rise time is greater when the input voltage is less i.e. at $10 \mathrm{~V}$, the rise time at the 26 th stage is $27.34 \mathrm{~ms}$, while the rise time at $30 \mathrm{~V}$ input is $22.67 \mathrm{~ms}$.

\section{e. Practical vs Simulation analysis of Output voltage:} The proposed design was fabricated as shown in Fig 10. and the measured and simulated results were compared in Fig 11. it can be noted that there exists a goodmatch between the simulated and measured results.

To examine the dependency of the output voltage on the VDC, an experiment was conducted in which the VPP of the square wave was kept equal to the VDC and the obtained results were plotted as shown in Fig11. [a].
Figure 10: Fabricated proposed Dickson charge pump.



Figure 11: [a] Output voltage when VPP=VDC, [b] Output voltage when $\mathrm{VDC}=0 \mathrm{~V}$.

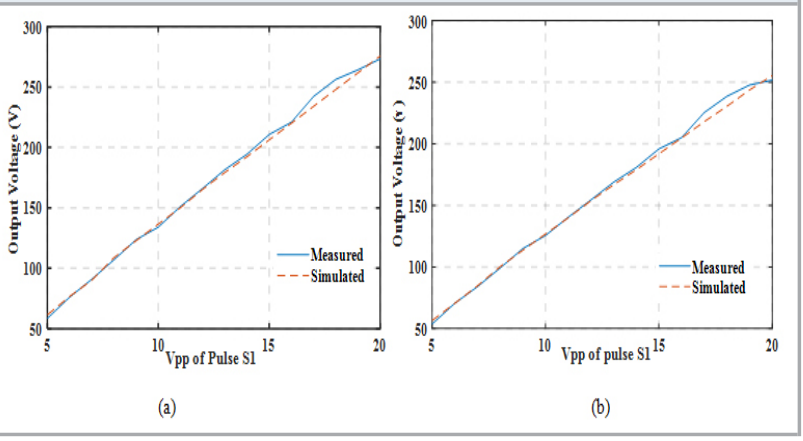

From the above experiment, it was found that the VDC is directly added to the output. Therefore,

Output voltage $=$ Boasted voltage + VDC

From Equation (3) we state that

$\mathrm{V}_{\mathrm{OUT}}=\mathrm{N}\left(\mathrm{V}_{\mathrm{PP}}-\mathrm{V}_{\mathrm{D}}\right)+\mathrm{V}_{\mathrm{DC}}$

Whereas, the dependency of the output voltage on the VPP of the square wave is given by equation (4), and it was examined in which the VDC was grounded and the results obtained were plotted as shown in Fig. 11. [b]. From the above experiment, it was found that the output voltage is boosted as the VPP increases. Therefore, the

$\mathrm{V}_{\mathrm{OUT}}=\mathrm{N}\left(\mathrm{V}_{\mathrm{PP}}-\mathrm{V}_{\mathrm{D}}\right)$

\section{CONCLUSION}

In this paper, a high-voltage-gain DC-DC converter is introduced that can offer a voltage gain of 14 , in order to step up a $30 \mathrm{~V}$ input to $400 \mathrm{~V}$ output which can be given as an input to the pulse generator of GPR. The power circuit consists of a controlling element which will prevent the continuous battery drainage problem caused by pulse generator and will supply power only when required. The minimum setup time of $42 \mathrm{~ms}$ was achieved at $100 \mathrm{KHz}$ with 50\% duty cycle and the voltage across the capacitor varies from $30 \mathrm{~V}$ to $400 \mathrm{~V}$, which indicates that it can be used to supply variable voltage. As the number of stages were increased the rise time also increased proportionally. The rise time at $10 \mathrm{~V}$ input on 
the 26th stage is $27.34 \mathrm{~ms}$, and the rise time at $30 \mathrm{~V}$ input is $22.67 \mathrm{~ms}$. From the practical analysis, it was found that the VOUT mainly depends on VPP whereas, VDC directly gets added to VOUT. The proposed converter is based on single-phase Dickson CP VM circuit. It can draw power from multiple sources offering continuous input current, making the converter well suited for RADAR application such as GPR and applications requiring high variable voltage.

\section{REFERENCES}

A.P Annan, 1999, Practical Processing of GRP data, Sensorft software INC, Proceedings of the Second Government Workshop on GroundPenetrating Radar, http://www.ees.nmt.edu/outside/courses/Geop446/ Docs/GPR_data_process.pdf.

Amir, A., Amir, A., Che, H.S., Elkhateb, A. and Abd Rahim, N., 2019. Comparative analysis of high voltage gain DC-DC converter topologies for photovoltaic systems. Renewable energy, 136, pp.1147-1163, doi: 10.1016/j.renene.2018.09.089.

Baddipadiga, B.P. and Ferdowsi, M., 2016. A highvoltage-gain dc-dc converter based on modified dickson charge pump voltage multiplier. IEEE Transactions on Power Electronics, 32(10), pp.7707-7715, doi: 10.1109/ TPEL.2016.2594016.

Cabrini, A., Gobbi, L. and Torelli, G., 2006, May. Theoretical and experimental analysis of Dickson charge pump output resistance. In 2006 IEEE International Symposium on Circuits and Systems (pp. 4-pp). IEEE, doi: 10.1109/ISCAS.2006.1693193.

Eoas.ubc.ca. (2018). GPR introduction. Available at: https://www.eoas.ubc.ca/courses/eosc350/content/ methods/gpr-06.htm [Accessed 28 0ct. 2018].

Fang, G.Y., Zhou, B., Ji, Y.C., Zhang, Q.Y., Shen, S.X., Li,
Y.X., Guan, H.F., Tang, C.J., Gao, Y.Z., Lu, W. and Ye, S.B., 2014. Lunar Penetrating Radar onboard the Chang'e-3 mission. Research in astronomy and astrophysics, 14(12), p.1607, doi: 10.1088/1674-4527/14/12/009.

Fisher, S.C., Stewart, R.R. and Jol, H.M., 1992. Processing ground penetrating radar (GPR) data. GPR Processing CREWES Research Report, 4, pp.11-1, doi: 10.4133/ JEEG 1.2.89.

Labunets, L.V., 2015. Automatic intellectual signal processing in subsurface radar systems. Journal of Communications Technology and Electronics, 60(4), pp.362-374, doi: 10.1134/S1064226915030122.

Pilawa-Podgurski, R.C. and Perreault, D.J., 2012. Merged two-stage power converter with soft charging switchedcapacitor stage in $180 \mathrm{~nm}$ CMOS. IEEE Journal of Solid-State Circuits, 47(7), pp.1557-1567, doi : 10.1109/ JSSC.2012.2191325.

Prabhala, V.A.K., Baddipadiga, B.P. and Ferdowsi, M., 2014, October. DC distribution systems-An overview. In 2014 International Conference on Renewable Energy Research and Application (ICRERA) (pp. 307-312). IEEE, doi: 10.1109/ICRERA.2014.7016575.

Santoja, A., Barrado, A., Fernandez, C., Sanz, M., Raga, C. and Lazaro, A., 2013, March. High voltage gain DC-DC converter for micro and nanosatellite electric thrusters. In 2013 Twenty-Eighth Annual IEEE Applied Power Electronics Conference and Exposition (APEC) (pp. 2057-2063). IEEE, doi : 10.1109/APEC.2013.6520579. Soldovieri, F., Leone, G., Liseno, A., Tartaglione, F. and Pierri, R., 2005. Linear tomographic inversion of stepped-frequency GPR data: experimental results on two test-sites. AEU-International Journal of Electronics and Communications, 59(6), pp.329-336, doi:10.1016/j. aeue.2004.11.043. 